\title{
Inovação: uma saída para o setor saúde
}

\author{
Imovation analtemativefor thehedthsedtor
}

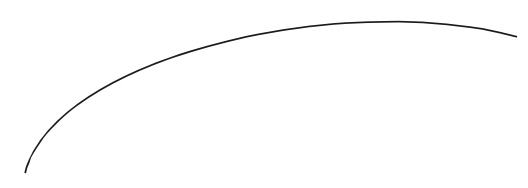

A Revista Brasileira de Geriatria e Gerontologia vem cumprindo de forma magnífica sua missão de abordar de forma contemporânea os temas relevantes na área gerontológica. Basta olhar para a diversidade de pesquisadores de inúmeros estados brasileiros que estão submetendo seus artigos para a Revista e, principalmente, o fato de a maioria desses artigos retratarem novas concepções, pautadas por um eixo central, da valorização do cuidado integral e da promoção e prevenção da saúde dos idosos.

Como estamos falando em contemporaneidade, um fato relevante, e que certamente irá despertar o interesse de muitos pesquisadores, foi o que ocorreu neste final de agosto. A Agência Nacional de Saúde Suplementar (ANS) publicou, no Diário Oficial da União, a Resolução Normativa $\mathrm{n}^{\circ} 265$, que incentiva a participação de beneficiários de planos de saúde em programas de envelhecimento ativo, com a possibilidade de descontos nas mensalidades. $\mathrm{Ou}$ seja, estimula-se a adesão dos beneficiários a programas de envelhecimento ativo, incentivando as operadoras a adotarem essa perspectiva de cuidados. Assim, idosos passam a receber benefícios pecuniários para aderir a programas de saúde preventiva e detecção precoce de doenças. $\mathrm{O}$ objetivo da resolução é incitar o setor a se pautar pela prevenção, pelo cuidado com a saúde, e não mais pelo tratamento das doenças. A iniciativa é bem-vinda.

Nossa população vem envelhecendo de forma acelerada. Todo ano, 700 mil novos idosos são incorporados à pirâmide etária brasileira - a maior parte com doenças crônicas, alguns com limitações funcionais. Em menos de 40 anos, passamos de um cenário de mortalidade próprio de uma população jovem para um quadro de enfermidades complexas e onerosas, com doenças que perduram por anos, exigem cuidados constantes, medicação contínua e exames periódicos. $\mathrm{O}$ aumento da expectativa de vida é positivo, mas é preciso agregar qualidade aos anos adicionais de vida.

Idosos apresentam maior carga de doenças e incapacidades e usam com mais frequência os serviços de saúde. Além disso, os modelos vigentes de atenção à saúde do idoso se mostram ineficientes e de alto custo. Qualquer política contemporânea de saúde deve valorizar o envelhecimento saudável, com manutenção e melhoria da capacidade funcional, prevenção de doenças, recuperação da saúde e/ ou estabilização das enfermidades e reabilitação das capacidades funcionais restringidas.

Os planos de saúde operam numa espécie de mutualismo, em que os menos saudáveis consomem mais serviços e inflacionam valores pagos por quem está em boa forma. As empresas terão de se adaptar, pois não é cabível manter a lógica da doença. A resolução da ANS implica 
reorganizar os serviços de saúde e oferece mecanismos de indução também para consumidores, cuja adesão é fundamental para o sucesso das ações preventivas. A iniciativa assume as particularidades do idoso e o situa como protagonista no sistema de saúde.

A relação entre prestadoras e clientes de mais idade é pautada pela desconfiança. As operadoras procuram reduzir o peso desse segmento em suas carteiras e os idosos reclamam de preços e dificuldades de atendimento. Não existe outra relação de comércio em que vendedor e clientes têm posições tão antagônicas.

Algumas empresas talvez argumentem que programas de envelhecimento ativo poderão intensificar a utilização dos planos. Ou que o aumento da sinistralidade, o desconto concedido no preço e a obrigatoriedade de sua manutenção por 12 meses inviabilizam a proposta. Mas é preciso entender que prevenção e promoção de saúde, se bem aplicadas e corretamente avaliadas, podem trazer resultados financeiros positivos no médio e longo prazos. No início, aumenta o uso de procedimentos, principalmente de baixo custo, mas depois há uma redução dos procedimentos de alto custo, aliada à melhoria da saúde. Talvez o mais difícil seja a mudança de cultura.

Sem uma abordagem preventiva e integral que associe reflexão epidemiológica e planejamento sistemático de ações de saúde, não há saída possível para a crise de financiamento e reestruturação do setor.

A Revista Brasileira de Geriatria e Gerontologia incita este debate e está certa de que seu papel é encorajar mudanças, particularmente aquelas advindas do meio acadêmico. 